\title{
Recurrent mutations of BRCA1, BRCA2 and (a) CrossMark PALB2 in the population of breast and ovarian cancer patients in Southern Poland
}

\author{
P. Wojcik', M. Jasiowka², E. Strycharz ${ }^{1}$, M. Sobol ${ }^{1}$, D. Hodorowicz-Zaniewska ${ }^{3}$, P. Skotnicki ${ }^{4}$, T. Byrski ${ }^{6}$, P. Blecharz ${ }^{2}$, \\ E. Marczyk ${ }^{2}$, I. Cedrych ${ }^{2}$, J. Jakubowicz ${ }^{2}$, J. Lubiński ${ }^{7}$, V. Sopik ${ }^{8}$, S. Narod ${ }^{8}$ and P. Pierzchalski ${ }^{1,5^{*}}$
}

\begin{abstract}
Background: Mutations in the BRCA1, BRCA2 and PALB2 genes are well-established risk factors for the development of breast and/or ovarian cancer. The frequency and spectrum of mutations in these genes has not yet been examined in the population of Southern Poland.

Methods: We examined the entire coding sequences of the BRCA1 and BRCA2 genes and genotyped a recurrent mutation of the PALB2 gene (c.509_510delGA) in 121 women with familial and/or early-onset breast or ovarian cancer from Southern Poland.

Results: A BRCA1 mutation was identified in 11 of 121 patients $(9.1 \%)$ and a BRCA2 mutation was identified in 10 of 121 patients (8.3\%). Two founder mutations of BRCA1 accounted for $91 \%$ of all BRCA1 mutation carriers (c.5266dupC was identified in six patients and c.181 T> G was identified in four patients). Three of the seven different BRCA2 mutations were detected in two patients each (c.9371A > T, c.9403delC and c.1310_1313delAAGA). Three mutations have not been previously reported in the Polish population (BRCA1 c.3531delT, BRCA2 c.1310_1313delAAGA and BRCA2 c.9027delT). The recurrent PALB2 mutation c.509_510delGA was identified in two patients (1.7\%).

Conclusions: The standard panel of BRCA1 founder mutations is sufficiently sensitive for the identification of BRCA1 mutation carriers in Southern Poland. The BRCA2 mutations c.9371A > T and c.9403delC as well as the PALB2 mutation c.509_510delGA should be included in the testing panel for this population.
\end{abstract}

Keywords: BRCA1, BRCA2, PALB2, Breast cancer, Ovarian cancer

\section{Background}

Inherited mutations in the DNA repair genes BRCA1 and BRCA2, discovered and cloned almost 20 years ago, are associated with significantly increased risks of both breast and ovarian cancer [1-6]. The BRCA1/2 proteins participate in molecular repair pathways in response to DNA damage; BRCA1 is involved in the recognition of DNA damage and the regulation of cell cycle arrest and BRCA2 regulates the key homologous recombination enzyme Rad51 [7-14]. In addition to BRCA1/2, several

\footnotetext{
* Correspondence: ppierzchalski@oncogene.pl

'Oncogene Diagnostics, Mogilska 86, 31-546 Kraków, Poland

${ }^{5}$ Faculty of Health Science, Department of Medical Physiology, Jagiellonian

University Medical College, Cracow, Poland

Full list of author information is available at the end of the article
}

other genes have been identified which predispose women to breast and/or ovarian cancer. Genes with high penetrance (i.e. relative risk of four or more) include TP53, PTEN and PALB2 [15-17]. Genes with moderate or low penetrance (i.e. relative risk of 1.5 to 3 ) include ATM, CHEK2, NBS1, and BRIP1 [18-21].

In Poland, a relatively small number of founder mutations in genes of high or moderate penetrance account for the majority of breast and/or ovarian cancer families. Among them are six mutations of BRCA1 (c.68_69delAG, c.181 T > G, c.3700_3704del, c.4035delA, c.5266dup and c.5251C $>$ T) of BRCA1 mutations, a single mutation of NBS1 (c.657_661delACAAA) and two recently described mutations of PALB2 (c.509_510delGA and c.172_ 175delTTGT) [21-23]. Some recurrent mutations of 
BRCA2 have been reported (c.658_659delGT, c.3847 3848delGT, c.5239_5240insT, c.5946delT and c.7913_ 7917del), but the frequency of these mutations in Polish families is relatively low [19, 23, 24]. Kluska et al. recently proposed that the testing panel of Polish founder mutations be expanded to include two new mutations, c. $1687 \mathrm{C}>\mathrm{T}$ in BRCA1 and c.9371A $>\mathrm{T}$ in BRCA2 with the status pathogenic and likely pathogenic respectively, which showed strong founder effects in Polish patients with familial or early-onset breast and/or ovarian cancer [25]. Although the set of the most frequent deleterious mutations described above is generally accepted, there have been significant discrepancies in the frequency of recurrent mutations reported in different regions of Poland. Based on the data published previously by different Polish groups, we have decided that the set of five BRCA1 mutations (c.68_69delAG, c.181 T > G, c.3700_3704del, c.4035delA, c.5266dup), which is covering approximately $90 \%$ of all detected in BRCA1 mutations associated with familial breast and ovarian cancer syndrome might be treated as a "standard panel" for Polish population [21, 23, 26-28].

The aim of our study was to identify the optimal panel of founder mutations for the genetic screening of patients at high risk for hereditary breast and/or ovarian cancer in Southern Poland. We compared the frequency and spectrum of BRCA1 and BRCA2 mutations contributing to breast and ovarian cancer families in Malopolska with those that have been previously reported in Polish families. We also examined the frequency of the recurrent PALB2 deletion c.509_510delGA in this population.

\section{Methods}

\section{Patient group}

We studied 121 women diagnosed with breast or ovarian cancer from families fulfilling one of the following criteria: 1) three or more breast and/or ovarian cancer cases in first or second-degree relatives, 2) synchronous or metachronous breast and/or ovarian cancer in the same patient, 3) two breast cancer cases in first-degree relatives (at least one diagnosed before age 50) or 4) breast cancer diagnosed before age 40 . All patients in the study were recruited between 2012 and 2014 from three oncology centers in Małopolska: (i) Oncology Cancer Center Institute Marie Skłodowska-Curie, Department in Kraków, (ii) Outpatient Clinic of Early Diagnosis and Treatment of Breast Disease, Collegium Medicum Jagiellonian University, Kraków and (iii) Outpatient Clinic of Oncological Surgery, St. Raphael Hospital, Kraków. Written consent for genetic testing was obtained for all patients. This study was approved by the Ethics Committee (decision No. 71/KBL/OIL/ 2012).

\section{DNA isolation}

Genomic DNA was isolated from $200 \mathrm{ul}$ of peripheral blood on Extractme silica columns (EURx) according to the manufacturer's protocol. The quality and concentration of extracted DNA was assessed using NanoDrop 2000 (ThermoScientific).

\section{HRM analysis}

The BRCA1 coding sequence with flanking intronic sequences were analyzed for all patients using the High Resolution Melting (HRM) method. The HRM method is a commonly used for the detection of single nucleotide substitutions and small oligonucleotide insertion or deletion variants and has been shown to be suitable for the detection of BRCA1 mutations [29-31]. Primers were designed to amplify a fragment no longer than $300 \mathrm{bp}$ to enable mutation detection. Coding sequences longer than $300 \mathrm{bp}$ were covered with amplicons with overlapping flanking sequences. Optimal annealing temperature was established employing gradient PCR. Agarose gels were run for each primer set to ensure that the correct size product was produced and that there was no formation of non-specific products. The thermal cycling profile consisted of a three minute initial activation at $95{ }^{\circ} \mathrm{C}, 453$-step cycles $\left(5 \mathrm{~s}\right.$ denaturation at $95{ }^{\circ} \mathrm{C}$, annealing for $10 \mathrm{~s}, 10 \mathrm{~s}$ extension at $72{ }^{\circ} \mathrm{C}$ ) and a final hold at $72{ }^{\circ} \mathrm{C}$ for $10 \mathrm{~s}$. For the HRM analysis, fluorescence data acquisition was set from $77{ }^{\circ} \mathrm{C}$ to $89{ }^{\circ} \mathrm{C}$, increasing the temperature by $0.1{ }^{\circ} \mathrm{C}$ each step. $20 \mathrm{ng}$ of genomic DNA was added to the PCR mix containing primers pair and SensiFAST HRM kit (Bioline). 42 amplicons were used to analyze the BRCA1 sequence. A known homozygous wild type control and a no-template control were also included in the analyzed sample sets. The analysis was performed on Rotor-Gene Q 5plex HRM Platform (Qiagen). Samples with an aberrant melting profile were sequenced using Sanger sequencing.

\section{DNA sequencing}

The BRCA2 coding sequence with flanking intronic sequence and the PALB2 mutation c.509_510delGA were analyzed for all patients using Sanger sequencing. Amplicons were sequenced using BigDye Terminator v3.1 Cycle Sequencing Kit and 3130xl Genetic Analyzer (Applied Biosystems). Sequencing data were examined using Sequencing Analysis software 5.2 and compared to reference sequences. Nucleotide reference sequences were as follows: BRCA1 (NM_007294.3, NG_005905.2), BRCA2 (NM_000059.3, NG_012772.3), PALB2 (NM 024675.3, NG_007406.1). Each detected mutation was confirmed by independent analysis starting from DNA extraction. 


\section{Results}

We screened 121 women with familial and/or earlyonset breast or ovarian cancer for mutations in BRCA1, BRCA2 and PALB2. The mean age of cancer diagnosis for all patients was 48.5 years (range $27-85$ years). There were 115 women with breast cancer (mean age of diagnosis: 48.6 years) and six women with ovarian cancer (mean age of diagnosis: 46.7 years).

A mutation in one of the three genes was detected in 23 of 121 patients (19.0\%). A BRCA1 mutation was identified in 11 patients $(9.1 \%)$ and a BRCA2 mutation was identified in ten patients ( $8.3 \%)$. The PALB2 mutation c.509_510delGA was identified in two patients (1.7\%). Molecular and clinical characteristics of the mutationpositive patients are presented in Table 1.

Two common founder mutations of BRCA1 accounted for $91 \%$ of all BRCA1 mutation carriers. The BRCA1 founder mutation c.5266dupC was identified in six patients ( $54.5 \%$ of all BRCA1 carriers), and the BRCA1 founder mutation c.181 T > G was identified in four patients (36.4 \% of all BRCA1 carriers). One patient was found to carry a rare BRCA1 mutation c.3531delT (9.1\% of all BRCA1 carriers). This variant has not been previously reported in the Polish population (Table 2).

In the group of 10 patients harboring BRCA2 mutations, seven different single mutations have been detected. Three mutations (c.1310_1313delAAGA, c.9371A > T and c.9403delC) were identified in two patients each and four mutations (c.6267_6269delinsC, c.9027delT, c.7913_7917 delTTCCT and c.10095delCinsGAATTATATCT) were identified in one patient each. Two of the BRCA2 mutations (c.1310_1313delAAGA and c.9027delT) have not been previously reported in the Polish population (Table 3).

In addition to the pathogenic mutations described above, several synonymous and non-synonymous variants

Table 1 Molecular and clinical characteristics of mutation-positive patients

\begin{tabular}{|c|c|c|c|c|c|}
\hline Patient & Type of cancer & Mutation & Age of onset & $\begin{array}{l}\text { Number of ovarian } \\
\text { cancers in family }\end{array}$ & $\begin{array}{l}\text { Number of breast } \\
\text { cancers in family }\end{array}$ \\
\hline \multicolumn{6}{|l|}{ BRCA1 } \\
\hline 1 & Breast cancer & \multirow{4}{*}{$\begin{array}{l}\text { c.181 T > G, p.C61G } \\
\text { "standard panel" mutation }\end{array}$} & 43 & 2 & 0 \\
\hline 2 & Bilateral breast & & $35 / 42$ & 0 & 6 \\
\hline 3 & Breast cancer & & 42 & 2 & 0 \\
\hline 4 & Breast cancer & & 25 & 2 & 2 \\
\hline 5 & Ovarian cancer & c.3531delT, p.F1177Lfs*33 & 39 & 1 & 0 \\
\hline 6 & Breast cancer & \multirow{6}{*}{$\begin{array}{l}\text { c.5266dupC, p.Q1756Pfs*74 } \\
\text { "standard panel" mutation }\end{array}$} & 59 & 3 & 0 \\
\hline 7 & Ovarian cancer & & 59 & 4 & 0 \\
\hline 8 & Breast cancer & & 44 & 0 & 1 \\
\hline 9 & Breast cancer & & 55 & 1 & 0 \\
\hline 10 & Breast cancer & & 44 & 1 & 1 \\
\hline 11 & Bilateral breast & & 25 & 1 & 0 \\
\hline \multicolumn{6}{|l|}{ BRCA2 } \\
\hline 1 & Breast cancer & \multirow{2}{*}{$\begin{array}{l}\text { c.1310_1313delAAGA, } \\
\text { p.Lys437llefs*22 }\end{array}$} & 37 & 0 & 1 \\
\hline 2 & Breast cancer & & 38 & 0 & 4 \\
\hline 3 & Breast cancer & $\begin{array}{l}\text { c.6267_6269delinsC, } \\
\text { p.E2089_H2090delinsDfs*2 }\end{array}$ & 41 & 0 & 3 \\
\hline 4 & Bilateral breast & c.7913_7917delTTCCT, p.F2638* & 40 & 0 & 1 \\
\hline 5 & Breast cancer & c.9027delT, p.Y3009Yfs*19 & 52 & 1 & 1 \\
\hline 6 & Breast cancer & c.9371 A > T, p.N3124l & 67 & 1 & 1 \\
\hline 7 & Bilateral breast & & - & 2 & 1 \\
\hline 8 & Bilateral breast & c.9403delC, p.L3135Ffs*28 & 36 & 0 & 1 \\
\hline 9 & Breast cancer & & 37 & 2 & 1 \\
\hline 10 & Breast cancer & $\begin{array}{l}\text { c.10095delCinsGAATTATATCT, p.V3365Vfs*5 } \\
\text { (non-pathogenic) }\end{array}$ & 61 & 0 & 1 \\
\hline \multicolumn{6}{|l|}{ PALB2 } \\
\hline 1 & Breast cancer & c.509_510delGA & $<50$ & 0 & 1 \\
\hline 2 & Breast cancer & & 48 & 0 & 2 \\
\hline
\end{tabular}


Table 2 Frequency of rare (non-founder) BRCA1 mutations reported in the Polish population

\begin{tabular}{|c|c|c|c|c|c|c|c|c|c|c|c|}
\hline \multirow[t]{2}{*}{ BRCA1 mutation } & \multirow{2}{*}{$\begin{array}{l}\text { Perkowska } \\
\text { (2003) } \\
{[39]} \\
N=60\end{array}$} & \multirow{2}{*}{$\begin{array}{l}\text { Górski } \\
(2004) \\
{[32]} \\
N=200\end{array}$} & \multirow{2}{*}{$\begin{array}{l}\text { Brożek } \\
(2008) \\
{[35]} \\
n=151\end{array}$} & \multirow{2}{*}{$\begin{array}{l}\text { Ratajska } \\
(2008) \\
{[26]} \\
N=64\end{array}$} & \multirow{2}{*}{$\begin{array}{l}\text { Rzepecka } \\
(2012) \\
{[54]} \\
n=257\end{array}$} & \multirow{2}{*}{$\begin{array}{l}\text { Gaj } \\
(2012) \\
{[55]} \\
n=906\end{array}$} & \multirow{2}{*}{$\begin{array}{l}\text { Cybulski } \\
(2014) \\
{[24]} \\
n=144\end{array}$} & \multirow{2}{*}{$\begin{array}{l}\text { Ratajska } \\
(2015) \\
{[27]} \\
n=134\end{array}$} & \multirow{2}{*}{$\begin{array}{l}\text { Szwiec } \\
(2015) \\
{[49]} \\
n=1164\end{array}$} & \multirow{2}{*}{$\begin{array}{l}\text { Kluska } \\
(2015) \\
{[2015]} \\
n=512\end{array}$} & \multirow{2}{*}{$\begin{array}{l}\text { Current } \\
\text { study } \\
n=121\end{array}$} \\
\hline & & & & & & & & & & & \\
\hline c.342_343delTC & - & - & - & - & - & - & - & - & - & 1 & - \\
\hline c.405_408delAAGA & - & - & - & - & - & - & - & - & - & 1 & - \\
\hline c.406delA & - & - & - & - & - & - & - & - & - & 1 & - \\
\hline C. $594-2 A>C$ & - & - & - & - & - & - & - & 1 & - & - & - \\
\hline c.676delT & - & 2 & - & - & - & - & - & - & - & - & - \\
\hline c. $1612 C>T$ & - & - & - & - & - & - & - & - & - & 1 & - \\
\hline c. $1687 \mathrm{C}>\mathrm{T}$ & - & - & 2 & - & - & - & 1 & - & - & 8 & - \\
\hline c.1695_1696insG & - & - & - & - & - & - & - & - & - & 1 & - \\
\hline c.1793 T>A & - & - & - & - & - & - & - & 1 & - & - & - \\
\hline c. $2563 C>T$ & 1 & - & - & - & - & - & - & - & - & - & - \\
\hline c.2866_2870delTCTCA & - & 1 & - & - & - & - & - & - & - & - & - \\
\hline c.2872_2876delTTCAG & - & - & - & 1 & - & - & - & - & - & - & - \\
\hline c.3531delT & - & - & - & - & - & - & - & - & - & - & 1 \\
\hline$c .3748 G>T$ & - & - & - & - & 1 & - & - & - & - & - & - \\
\hline c.3756_3759delGTCT & - & - & - & - & 3 & 4 & - & - & - & - & - \\
\hline c.3779delT & - & - & - & - & - & 2 & - & - & - & - & - \\
\hline c. $3817 C>T$ & - & - & - & 1 & - & - & - & - & - & - & - \\
\hline c.4041_4042delAG & - & - & - & - & - & 1 & 1 & - & - & - & - \\
\hline$c .4357+2 \mathrm{~T}>\mathrm{G}$ & - & - & - & - & - & - & - & 1 & - & - & - \\
\hline$c .4484+1 G>A$ & 1 & - & 1 & - & - & - & - & - & - & - & - \\
\hline c.4516delG & - & - & - & - & - & - & - & - & - & 4 & - \\
\hline c.4597_4598delGA & - & - & - & - & - & - & - & - & - & 1 & - \\
\hline c. 4689 C > G & - & - & - & - & - & - & - & - & - & 1 & - \\
\hline c.5030_5033delCTAA & - & 1 & - & - & - & - & - & - & - & - & - \\
\hline c.5095C > T & - & - & - & - & - & - & - & - & - & 2 & - \\
\hline c.5137delG & - & - & - & - & - & - & - & - & - & 1 & - \\
\hline c.5177_5180delGAAA & - & - & - & - & - & - & 1 & - & - & - & - \\
\hline c.5232del7ins 12 & - & - & - & - & - & - & - & - & - & 1 & - \\
\hline$c .5251 C>T$ & - & 3 & - & - & - & 8 & 1 & - & 3 & - & - \\
\hline c.5289insG & - & - & - & - & - & - & - & - & - & 1 & - \\
\hline$c .5346 G>A$ & 1 & - & - & - & - & - & 1 & - & - & 2 & - \\
\hline
\end{tabular}

$\mathrm{n}$ - represents number of patients included to the study; $\mathrm{N}$ - represents number of families included to the study

were detected in the analyzed genes, including ten in BRCA1 (c.734A $>$ T, c.1067A $>$ G, c.2077 G > A, c.20 $82 \mathrm{C}>$ T, с. 2311 T $>$ C, с. $3113 \mathrm{~A}>\mathrm{G}$, с. $3548 \mathrm{~A}>\mathrm{G}$, c. 403 9A > G, c.4308 T>C, c.4837A > G), nine in BRCA2 (c.33 $96 \mathrm{~A}>\mathrm{G}$, c.3516 G>A, c.3807 T > C, c.5199 C > T, c.57 $44 \mathrm{C}>\mathrm{T}$, c.7242A $>\mathrm{G}$, c. $8182 \mathrm{G}>\mathrm{A}$, c. $8850 \mathrm{G}>\mathrm{T}$, c. 1020 $2 \mathrm{C}>\mathrm{T}$ ) and one in PALB2 (c.1010 $\mathrm{T}>\mathrm{C}$ ).

Two of the 11 BRCA1 mutations were identified in women with high-grade serous ovarian cancer and nine were identified in women with breast cancer. Of the six BRCA1 mutation-associated breast cancers with information on histopathology, hormone receptor status and HER2 status, four were triple-negative (ER/ PR/HER2-negative) invasive ductal carcinomas and two were atypical medullary breast cancers (ER/PR-positive, HER2-negative). All nine BRCA2 mutations were identified in women with breast cancer. Of the eight BRCA2 mutation-associated breast cancers with information on histopathology, hormone receptor status and HER2 status, five were ER/PR-positive, HER2-negative invasive ductal carcinomas and three were ER/PRpositive, HER2-positive invasive ductal carcinomas. Both 
Table 3 Overview of mutations found in the BRCA2 gene in the Polish population

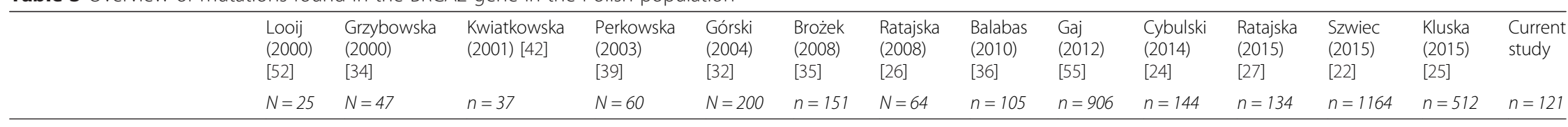

c.22_23delAG

c.262_263delCT

c. $274 \mathrm{C}>\mathrm{T}$

c.658_659delGT

c.700delT

c.1180G > T

c.1310_1313delAAGA

C.1318_1321delCTTA

c.1813_1814insA

c.2806_2809delAAAC

c.2808_2811delACAA

c.3199delA

c.3847_3848delGT

c.3860delA

c.3975_3981dupTGCT

c.4223delA

c.5042_5043delTG

c.5239_5240insT

c.5722_5723delCT

c.5946delT

c.5964_5965delAT

c.6010_6030delinsTT

c.6267_6269delGCAinsC

c.6275_6276delTT

c.6393_6396delATTA

c.6402_6406deITAACT

c.6447_6448delTA

c.6658_6662delGAAAA

c. $7007 \mathrm{G}>\mathrm{A}$ 
Table 3 Overview of mutations found in the BRCA2 gene in the Polish population (Continued)

\begin{tabular}{|c|c|c|c|c|c|c|c|c|c|c|c|c|c|c|}
\hline c.7180A > T & - & - & - & - & - & - & - & - & - & - & 1 & - & - & - \\
\hline c.7251_7252delCA & - & - & - & - & - & - & - & - & - & 1 & - & - & 1 & - \\
\hline c.7080_7099dup & 1 & - & - & - & - & - & - & - & - & - & - & - & - & - \\
\hline c.7913_7917delTTCCT & - & - & 1 & - & 1 & - & - & 3 & 2 & - & - & 1 & - & 1 \\
\hline c.8648delC & - & - & - & - & - & - & 1 & - & - & 1 & - & - & - & - \\
\hline c.8842delA & 1 & - & - & - & 1 & - & - & - & - & - & - & - & 1 & - \\
\hline c.8924delT & - & - & - & - & - & - & - & 1 & 1 & - & - & - & - & - \\
\hline c.8946delA & - & - & - & - & - & - & - & - & - & - & - & - & 1 & - \\
\hline c.9027delT & - & - & - & - & - & - & - & - & - & - & - & - & - & 1 \\
\hline c.9097_9098insA & - & - & - & - & - & - & - & 1 & - & 1 & - & - & - & - \\
\hline$c .9118-2 A>G$ & - & - & - & - & - & - & - & 1 & - & - & - & - & 3 & - \\
\hline c.9138C > T & - & - & - & - & - & - & - & - & - & - & - & - & 1 & - \\
\hline c.9253_9254insA & - & - & - & - & - & - & - & - & - & 1 & - & - & - & - \\
\hline c.9371A > T & - & 1 & 1 & - & - & - & - & 3 & - & - & - & - & 6 & 2 \\
\hline c.9376delC & - & - & - & - & - & - & - & - & - & - & - & - & 1 & - \\
\hline c.9403delC & - & 3 & - & - & 1 & - & - & 1 & - & 1 & - & - & - & 2 \\
\hline c.10095delCinsGAATTATATCT & - & - & - & - & - & - & 2 & 1 & - & - & - & - & - & 1 \\
\hline
\end{tabular}

$\mathrm{n}$ - represents number of patients included to the study; $\mathrm{N}$ - represents number of families included to the study 
PALB2 mutation-associated breast cancers were ER/PRpositive invasive ductal carcinomas with coexisting ductal carcinoma in situ.

\section{Discussion}

We identified a BRCA1/2 mutation in 21 (17.4\%) of 121 patients with familial and/or early-onset breast or ovarian cancer from Southern Poland. A BRCA1 mutation was identified in 11 patients $(9.1 \%)$ and a BRCA2 mutation was identified in ten patients $(8.3 \%)$. The prevalence of BRCA1/2 mutations is relatively low compared to previous studies of Polish breast and/or ovarian cancer families, in large part due to the low frequency of BRCA1 mutations. In a study of 200 Polish families with three or more breast or ovarian cancers a BRCA1/2 mutation was identified in $64 \%$; the prevalence of BRCA1 mutations was $60 \%$ and the prevalence of BRCA2 mutations was $4 \%$ [32]. In a study of Northern Polish families with similar characteristics as the families in our study, a BRCA $1 / 2$ mutation was identified in $67 \%$; the prevalence of BRCA1 mutations was $61 \%$ and the prevalence of BRCA2 mutations was $6 \%$ [26]. The relatively low frequency of BRCA1 mutations reported here may be explained by a lower prevalence of mutations in this particular region of Poland, noticed and reported previously by Blecharz et al and Brozek et al $[28,33]$. The frequency of BRCA2 mutations in this study (8.3\%) is within the range of mutation frequencies reported in previous studies of Polish families (2.6 to $11.4 \%$ ) [24, 34-37].

The two most frequent mutations identified in the present study were the BRCA1 founder mutations c.5266dupC (identified in six patients) and c.181 T > G (identified in four patients). These two founder mutations accounted for $91 \%$ of all BRCA1 mutation carriers, which in general is consistent with previous studies in the Polish population (Table 4) [26, 33, 38, 39]. However, in our study BRCA1 founder mutations accounted for only $48 \%$ of all BRCA1 and BRCA2 mutation carriers, whereas in previous studies BRCA1 founder mutations accounted for 80 to $90 \%$ of all BRCA1/2 carriers [26, 28, 32]. In most previous studies there was a preponderance of BRCA1 mutations over BRCA2 mutations. In our study, the frequency of BRCA1 and BRCA2 mutations is similar, and BRCA2 mutations make a larger contribution to all BRCA1/2 mutation carriers. The relatively low ratio of BRCA1 to BRCA2 mutations reported here may be due to the low prevalence of BRCA1 founder mutations in this region (discussed above) or perhaps there has not been enough BRCA2 mutation screening in Poland because of the lack of founder mutations and more research is warranted. Nevertheless, it is of particular importance to identify recurrent mutations of BRCA2 in this population.
Three of the seven different BRCA2 mutations identified in the current study were recurrent (i.e. found in more than one patient). Two patients carried the likely pathogenic BRCA2 mutation c.9371A > T. This substitution is located in an evolutionarily conserved region of the BRCA2 gene and is predicted to adversely affect ssDNA interaction and the structural integrity of the Cterminal domain of the protein $[40,41]$. This variant has previously been reported in 11 unrelated patients from Poland (Table 3) $[25,34,36,42]$. Kluska et al recently identified the variant in six patients and proposed its inclusion in the list of Polish founder mutations [25]. Two patients carried the BRCA2 mutation c.9403delC. This mutation has been previously reported in six unrelated patients from Poland (Table 3), including three patients from Southern Poland [34]. The mutation has also been reported in patients from the Czech Republic and Slovakia $[43,44]$. This variant may be a local founder mutation and should be included as a part of the screening test for the Polish population. Two patients carried the BRCA2 mutation c.1310_1313delAAGA. This mutation has not been previously reported in other studies from Poland. However, it has been frequently reported in Denmark and less frequently in France, Spain and North Africa [45-47]. The prevalence of this mutation in Southern Poland should be examined further. Including the two recurrent BRCA2 mutations that have been previously identified in the Polish population (c.9371A > T and c.9403delC) in the standard testing panel would increase the sensitivity of the panel for all BRCA1/2 mutation carriers from 48 to $67 \%$.

One patient carried the BRCA2 frame-shift variant c.10095delCinsGAATTATATCT. This variant truncates the BRCA2 protein at the very end of the $\mathrm{C}$-terminus and according to the BIC database is most likely benign. We classified this variant as non-pathogenic, however there is one previous report which suggests a potential association of the variant with familial aggregation of breast and/or ovarian cancer [48]. Furthermore, in our family, the variant was identified in two first-degree relatives with breast cancer, including one patient who was diagnosed before age 50 . This variant has now been identified in four unrelated Polish patients (Table 3).

We identified the PALB2 mutation c.509_510delGA in two unrelated patients (1.7 \%), both of whom were diagnosed with breast cancer before age 50 and had one affected relative. This mutation was recently identified in $70(0.6 \%)$ of 12,529 unselected breast cancer patients from Poland, and is considered to be a recurrent mutation in the Polish population $[49,50]$. In a study of 144 Polish breast cancer families, the mutation was identified in $1.4 \%$ and accounted for $50 \%$ of all PALB2 mutation carriers [23]. The full spectrum of PALB2 mutations in the population of southern Poland is not known. The 
Table 4 Basic panel ("standard panel") of the five most common mutations identified in BRCA1 and their relative frequency in the Polish population

\begin{tabular}{|c|c|c|c|c|c|c|c|c|c|c|c|c|c|c|}
\hline Mutation & $\begin{array}{l}\text { Looij (2000) } \\
{[52]}\end{array}$ & $\begin{array}{l}\text { Grzybowska } \\
\text { (2000) [34] }\end{array}$ & $\begin{array}{l}\text { Grzybowska } \\
\text { (2002) [53] }\end{array}$ & $\begin{array}{l}\text { Perkowska } \\
(2003)[39]\end{array}$ & $\begin{array}{l}\text { Górski } \\
\text { (2004) [32] }\end{array}$ & $\begin{array}{l}\text { Górski } \\
\text { (2006) [38] }\end{array}$ & $\begin{array}{l}\text { Brożek } \\
\text { (2008) [35] }\end{array}$ & $\begin{array}{l}\text { Ratajska } \\
\text { (2008) [26] }\end{array}$ & $\begin{array}{l}\text { Blecharz } \\
\text { (2009) [28] }\end{array}$ & $\begin{array}{l}\text { Rzepecka } \\
\text { (2012) [54] }\end{array}$ & $\begin{array}{l}\text { Gaj } \\
(2012) \text { [55] }\end{array}$ & $\begin{array}{l}\text { Szwiec } \\
(2015) \text { [22] }\end{array}$ & $\begin{array}{l}\text { Ratajska } \\
(2015)[27]\end{array}$ & $\begin{array}{l}\text { Current } \\
\text { study }\end{array}$ \\
\hline c.5266dupC & $20 \%$ & $92 \%$ & $73 \%$ & $55 \%$ & $59 \%$ & $55 \%$ & $46 \%$ & $57 \%$ & $57 \%$ & $62 \%$ & $66 \%$ & $52 \%$ & $62 \%$ & $60 \%$ \\
\hline$c .181 \mathrm{~T}>\mathrm{G}$ & $60 \%$ & $8 \%$ & $13 \%$ & $27 \%$ & $27 \%$ & $21 \%$ & $8 \%$ & $24 \%$ & $29 \%$ & $16 \%$ & $22 \%$ & $25 \%$ & $15 \%$ & $40 \%$ \\
\hline c.4035delA & $0 \%$ & $0 \%$ & $0 \%$ & $0 \%$ & $10 \%$ & $12 \%$ & $8 \%$ & $0 \%$ & $8 \%$ & $5 \%$ & $1 \%$ & $4 \%$ & $0 \%$ & $0 \%$ \\
\hline c.3700_3704delGTAAA & $20 \%$ & $0 \%$ & $0 \%$ & $9 \%$ & $3 \%$ & $6 \%$ & $31 \%$ & $11 \%$ & \multirow{2}{*}{$6 \%$} & $14 \%$ & $6 \%$ & $12 \%$ & $23 \%$ & $0 \%$ \\
\hline c.68_69delAG & $0 \%$ & $0 \%$ & $13 \%$ & $9 \%$ & $1 \%$ & $6 \%$ & $8 \%$ & $8 \%$ & & $3 \%$ & $5 \%$ & $7 \%$ & $0 \%$ & $0 \%$ \\
\hline
\end{tabular}


prevalence of this mutation in unselected breast cancer patients in the neighboring countries is as follows: Germans $0.3 \%$, Russians $0.2 \%$ and Belarusians $0.3 \%$ [51].

PALB2 c.509_510delGA is one of two recurrent PALB2 mutations that have been recently described in the Polish population. The other mutation, c.172_175delTTGT, has been identified in $0.3 \%$ of unselected breast cancer patients and $0.7 \%$ of familial breast cancer patients from Poland $[23,49]$. Among families with three or more breast cancers, the detection rate of 509_510delGA and 172 175delTTGT PALB2 mutations increases to $4.6 \%$. The risk of developing breast cancer is more than four times higher in PALB2 mutation carriers compared to noncarriers. Among those who develop breast cancer, the risk of dying at ten years is two times higher for PALB2 mutation carriers compared to non-carriers $(\mathrm{HR}=2.3$; $p<0.0001$ ).

In summary, we have identified five recurrent mutations in women with familial and/or early-onset breast and/or ovarian cancer from Southern Poland; BRCA1 c.5266dupC in six patients (prevalence: $5 \%$ ), BRCA1 c.181 T > G in four patients (prevalence: $3.3 \%$ ), BRCA2 likely pathogenic c.9371A $>\mathrm{T}$ in two patients, (1.7\%), BRCA2 c.9403delC in two patients $(1.7 \%)$ and PALB2 c.509_510delGA in two patients (1.7\%). Including the three additional recurrent mutations to the standard testing panel of BRCA1 founder mutations would increase the mutation detection rate from 8.3 to $13.4 \%$.

\section{Conclusions}

Based on the results presented above and data from previous studies we conclude that (i) the "standard panel" of five BRCA1 founder mutations, described published previously by different Polish groups is sufficiently sensitive to identify BRCA1 mutation carriers in a screening test and (ii) the recurrent BRCA2 mutations N3124I and 9631delC as well as the recurrent PALB2 mutation c.509_510delGA could be included in the testing panel for the Southern Polish population. The proposed enlargement of the mutation set used for routine screening for familial and/or early-onset breast and/or ovarian cancer might turn-out to be beneficial for the patients.

\section{Competing interest}

The authors declare that they have no competing interests.

\section{Authors' contribution}

PW conception and design, acquisition of data, analysis and interpretation of data and drafting the manuscript and revising it critically for important intellectual content. MJ acquisition of data and revising the manuscript critically for intellectual content. ES acquisition of data and revising the manuscript critically for intellectual content. MS acquisition of data and revising the manuscript critically for intellectual content. $\mathrm{DHZ}$ acquisition of data and revising the manuscript critically for intellectual content. PS acquisition of data and revising the manuscript critically for intellectual content. TB acquisition of data and revising the manuscript critically for intellectual content. PB acquisition of data and revising the manuscript critically for intellectual content. EM acquisition of data and revising the manuscript critically for intellectual content. IC acquisition of data and revising the manuscript critically for intellectual content. JJ acquisition of data and revising the manuscript critically for intellectual content. JL acquisition of data and revising the manuscript critically for intellectual content. VS analysis and interpretation of data and drafting the manuscript and revising it critically for important intellectual content. SN conception and design, acquisition of data, analysis and interpretation of data and drafting the manuscript and revising it critically for important intellectual content. PP conception and design, acquisition of data, analysis and interpretation of data and drafting the manuscript and revising it critically for important intellectual content. All authors read and approved the final manuscript.

\section{Acknowledgments}

This paper was supported by the grant MRPO.02.02.01-12-0549/12.

\section{Author details}

${ }^{1}$ Oncogene Diagnostics, Mogilska 86, 31-546 Kraków, Poland. ${ }^{2}$ Department in Cracow, Oncology Cancer Center Institute Marie Skłodowska-Curie, Cracow, Poland. ${ }^{3}$ First Chair of General, Oncological, and Gastrointestinal Surgery, Jagiellonian University Medical College, Krakow, Poland. ${ }^{4}$ Outpatient Clinic of Oncological Surgery, St. Raphael Hospital, Cracow, Poland. ${ }^{5}$ Faculty of Health Science, Department of Medical Physiology, Jagiellonian University Medical College, Cracow, Poland. ${ }^{6}$ Clinic of Oncology, Pomeranian Medical University, International Hereditary Cancer Center, Szczecin, Poland. ${ }^{7}$ Pomeranian Medical University, International Hereditary Cancer Center, Szczecin, Poland.

${ }^{8}$ Women's College Research Institute, Women's College Hospital, Toronto, Canada.

Received: 13 August 2015 Accepted: 28 January 2016

Published online: 03 February 2016

\section{References}

1. Hall JM, Lee MK, Newman B, Morrow JE, Anderson LA, Huey B, et al. Linkage of early-onset familial breast cancer to chromosome 17q21. Science. 1990;250(4988):1684-9.

2. Wooster R, Neuhausen SL, Mangion J, Quirk Y, Ford D, Collins N, et al. Localization of a breast cancer susceptibility gene, BRCA2, to chromosome 13q12-13. Science. 1994;265(5181):2088-90.

3. Miki Y, Swensen J, Shattuck-Eidens D, Futreal PA, Harshman K, Tavtigian S, et al. A strong candidate for the breast and ovarian cancer susceptibility gene BRCA1. Science. 1994;266(5182):66-71.

4. Bowcock AM. Molecular cloning of BRCA1: a gene for early onset familial breast and ovarian cancer. Breast Cancer Res Treat. 1993;28(2):121-35.

5. Wooster R, Bignell G, Lancaster J, Swift S, Seal S, Mangion J, et al. Identification of the breast cancer susceptibility gene BRCA2. Nature. 1995;378(6559):789-92.

6. Tavtigian SV, Simard J, Rommens J, et al. The complete BRCA2 gene and mutations in chromosome 13q-linked kindreds. Nat Genet. 1996;12(3):333-7.

7. Jasin M. Homologous repair of DNA damage and tumorigenesis: the BRCA connection. Oncogene. 2002;21(58):8981-93.

8. Loke J, Pearlman A, Upadhyay K, Tesfa L, Shao Y, Ostrer H. Functional variant analyses (FVAs) predict pathogenicity in the BRCA1 DNA double-strand break repair pathway. Hum Mol Genet. 2015;24(11):3030-7.

9. Xu X, Weaver Z, Linke SP, Li C, Gotay J, Wang XW, et al. Centrosome amplification and a defective G2-M cell cycle checkpoint induce genetic instability in BRCA1 exon 11 isoform-deficient cells. Mol Cell. 1999; 3(3):389-95

10. Chen J, Silver DP, Walpita D, Cantor SB, Gazdar AF, Tomlinson G, et al. Stable interaction between the products of the BRCA1 and BRCA2 tumor suppressor genes in mitotic and meiotic cells. Mol Cell. 1998;2(3):317-28.

11. Chen PL, Chen CF, Chen Y, Xiao J, Sharp ZD, Lee WH. The BRC repeats in BRCA2 are critical for RAD51 binding and resistance to methyl methanesulfonate treatment. Proc Natl Acad Sci U S A. 1998;95(9):5287-92.

12. Chen CF, Chen PL, Zhong Q, Sharp ZD, Lee WH. Expression of BRC repeats in breast cancer cells disrupts the BRCA2-Rad51 complex and leads to radiation hypersensitivity and loss of $\mathrm{G}(2) / \mathrm{M}$ checkpoint control. J Biol Chem. 1999;274(46):32931-5.

13. Lo T, Pellegrini L, Venkitaraman AR, Blundell TL. Sequence fingerprints in BRCA2 and RAD51: implications for DNA repair and cancer. DNA Repair (Amst). 2003;2(9):1015-28. 
14. Chen JJ, Silver D, Cantor S, Livingston DM, Scully R. BRCA1, BRCA2, and Rad51 operate in a common DNA damage response pathway. Cancer Res. 1999:59(7 Suppl):1752s-6.

15. Gonzalez KD, Noltner KA, Buzin CH, Gu D, Wen-Fong CY, Nguyen VQ, et al. Beyond Li Fraumeni Syndrome: clinical characteristics of families with p53 germline mutations. J Clin Oncol. 2009;27(8):1250-6.

16. Tan MH, Mester JL, Ngeow J, Rybicki LA, Orloff MS. Lifetime cancer risks in individuals with germline PTEN mutations. Clin Cancer Res. 2012;18(2):400-7.

17. Rahman N, Seal S, Thompson D, Kelly P, Renwick A, Elliott A, et al. PALB2, which encodes a BRCA2-interacting protein, is a breast cancer susceptibility gene. Nat Genet. 2007;39(2):165-7.

18. Renwick A, Thompson D, Seal S, Kelly P, Chagtai T, Ahmed M, et al. ATM mutations that cause ataxiatelangiectasia are breast cancer susceptibility alleles. Nat Genet. 2006;38(8):873-5.

19. Meijers-Heijboer $H$, van den Ouweland A, Klijn J, Wasielewski M, de Snoo A, Oldenburg $R$ et al. Lowpenetrance susceptibility to breast cancer due to CHEK2 $\left.{ }^{*}\right) 1100$ delC in noncarriers of BRCA1 or BRCA2 mutations. Nat Genet. 2002;31(1):55-9.

20. Seal S, Thompson D, Renwick A, Elliott A, Kelly P, Barfoot R et al. Truncating mutations in the fanconi anemia gene BRIP1 are low-penetrance breast cancer susceptibility alleles. Nat Genet. 2006;38:1239-41.

21. Bogdanova N, Feshchenko S, Schürmann P, Waltes R, Wieland B, Hillemanns $P$ et al. Nijmegen Breakage Syndrome mutations and risk of breast cancer. Int J Cancer. 2008;122(4):802-6.

22. Szwiec M, Jakubowska A, Górski B, Huzarski T, Tomiczek-Szwiec J, Gronwald $J$ et al. Recurrent mutaitons of BRCA1 and BRCA2 in Poland: an update. Clin Genet. 2015;87(3):288-92.

23. Steffen J, Nowakowska D, Niwińska A, Czapczak D, Kluska A, Piatkowska M, et al. Germline mutations 657del5 of the NBS1 gene contribute significantly to the incidence of breast cancer in Central Poland. Int J Cancer. 2006;119(2):472-5.

24. Cybulski C, Lubiński J, Wokołorczyk D, Kuźniak W, Kashyap A, Sopik V, et al. Mutations predisposing to breast cancer in 12 candidate genes in breast cancer patients from Poland. Clin Genet. 2014;20.

25. Kluska A, Balabas A, Paziewska A, Kulecka M, Nowakowska D, Mikula M, et al. New recurrent BRCA1/2 mutations in Polish patients with familial breast/ ovarian cancer detected by next generation sequencing. BMC Med Genomics. 2015;8(1):19.

26. Ratajska M, Brozek I, Senkus-Konefka E, Jassem J, Stepnowska M, Palomba G, et al. BRCA1and BRCA2 point mutations and large rearrangements in breast and ovarian cancer families in NorthernPoland. Oncol Rep. 2008;19(1):263-8.

27. Ratajska M, Krygier M, Stukan M, Kuźniacka A, Koczkowska M, Dudziak M, et al. Mutational analysis of BRCA1/2 in a group of 134 consecutive ovarian cancer patients. Novel and recurrent BRCA1/2 alterations detected by next generation sequencing. J Appl Genet. 2015;56(2):193-8.

28. Blecharz P, Szatkowski W, Klimek M, Urbański K. The prevalence of BRCA1 mutations among families at high-risk of breast and ovarian cancer in province of Malopolska between 2004-2009. Przegl Lek. 2009;66(12):1046-8.

29. de Juan I, Esteban E, Palanca S. High-resolution melting analysis for rapid screening of BRCA1 and BRCA2 Spanish mutations. Breast Cancer Res Treat. 2009:115(2):405-14.

30. van der Stoep N, van Paridon CD, Janssens T. Diagnostic guidelines for high-resolution melting curve (HRM) analysis: an interlaboratory validation of BRCA1 mutation scanning using the 96-well LightScanner. Hum Mutat. 2009;30(6):899-909.

31. Takano EA, Mitchell G, Fox SB. Rapid detection of carriers with BRCA1 and BRCA2 mutations using high resolution melting analysis. BMC Cancer. 2008;8:59.

32. Górski B, Jakubowska A, Huzarski T, Byrski T, Gronwald J, Grzybowska E, et al. A high proportion of founder BRCA1 mutations in Polish breast cancer families. Int J Cancer. 2004;110(5):683-6.

33. Brozek I, Cybulska C, Ratajska M, Piatkowska M, Kluska A, Balabas A, et al. Prevalence of the most frequent BRCA1 mutations in Polish population. J Appl Genet. 2011;52(3):325-30.

34. Grzybowska E, Zientek H, Jasinska A, Rusin M, Kozlowski P, Sobczak K, et al. High frequency of recurrent mutations in BRCA1 and BRCA2 genes in Polish families with breast and ovarian cancer. Hum Mutat. 2000;16(6):482-90.

35. Brozek I, Ochman K, Debniak J, Morzuch L, Ratajska M, Stepnowska M, et al. High frequency of BRCA1/2 germline mutations in consecutive ovarian cancer patients in Poland. Gynecol Oncol. 2008:108(2):433-7.
36. Balabas A, Skasko E, Nowakowska D, Niwinska A, Blecharz P. Novel germline mutations in BRCA2 gene among breast and breast-ovarian cancer families from Poland. Fam Cancer. 2010;9(3):267-74.

37. Lalloo F, Varley J, Ellis D, Moran A, O'Dair L, Pharoah P, et al. Early Onset Breast Cancer Study Group. Prediction of pathogenic mutations in patients with early-onset breast cancer by family history. Lancet. 2003;361(9363):1101-2.

38. Górski B. Selected Aspects of Molecular Diagnostics of Constitutional Alterations in BRCA1 and BRCA2 Genes Associated with Increased Risk of Breast Cancer in the Polish Population. Hered Cancer Clin Pract. 2006;4(3):142-52.

39. Perkowska M, Brozek I, Wysocka B, Haraldsson K, Sandberg T, Johansson U, et al. BRCA1 and BRCA2 mutation analysis in breast-ovarian cancer families from northeastern Poland. Hum Mutat. 2003;21(5):553-4.

40. Biswas K, Das R, Eggington JM, Qiao H, North SL, Stauffer S, et al. Functional evaluation of BRCA2 variants mapping to the PALB2-binding and C-terminal DNA-binding domains using a mouse ES cell-based assay. Hum Mol Genet. 2012;21(18):3993-4006.

41. Guidugli L, Pankratz VS, Singh N, Thompson J, Erding CA, Engel C, et al. A classification model for BRCA2 DNA binding domain missense variants based on homology-directed repair activity. Cancer Res. 2013;73(1):265-75.

42. Kwiatkowska E, Teresiak M, Lamperska KM, Karczewska A, Breborowicz D, Stawicka M, et al. BRCA2 germline mutations in male breast cancer patients in the Polish population. Hum Mutat. 2001;17(1):73.

43. Konecny M, Milly M, Zavodna K. Molekularno-geneticka diagnostika hereditarneho karcinomu prsnika/ovarii: vysledky testovania mutacii v genoch BRCA1 a BRCA2. Onkologia (Bratisl). 2012;7(2):89-93.

44. Foretova L, Machackova E, Navratilova M, Pavlu H, Hruba M, Lukesova M, et al. BRCA1 and BRCA2 mutations in women with familial or early-onset breast/ovarian cancer in the Czech Republic. Hum Mutat. 2004;23(4):397-8.

45. Cherbal F, Bakour R, Adane S, Boualga K. BRCA1 and BRCA2 germline mutation spectrum in hereditary breast/ovarian cancer families from Maghrebian countries. Breast Dis. 2012;34(1):1-8.

46. Velasco Sampedro E, Esteban Cardenosa E, Infante SM. Molecular study of the BRCA1 and BRCA2 genes in 153 breast cancer families from Castilla and Leon (Spain): new nine unclassified variants identified. Med Clin (Barc). 2002;119(12):441-5.

47. Caputo S, Benboudjema L, Sinilnikova O. Description and analysis of genetic variants in French hereditary breast and ovarian cancer families recorded in the UMD-BRCA1/BRCA2 databases. Nucleic Acids Res. 2012;40:D992-1002.

48. Meindl A. German Consortium for Hereditary Breast and Ovarian Cancer. Comprehensive analysis of 989 patients with breast or ovarian cancer provides BRCA1 and BRCA2 mutation profiles and frequencies for the German population. Int J Cancer. 2002;97(4):472-80.

49. Cybulski C, Kluźniak W, Huzarski T, Wokołorczyk D, Kashyap A, Jakubowska A et al. Polish Hereditary Breast Cancer Consortium. Clinical outcomes in women with breast cancer and a PALB2 mutation: a prospective cohort analysis. Lancet Oncol. 2015;16(6):638-44.

50. Dansonka-Mieszkowska A, Kluska A, Moes J, Dabrowska M, Nowakowska D, Niwinska A, et al. A novel germline PALB2 deletion in Polish breast and ovarian cancer patients. BMC Med Genet. 2010;11:20.

51. Noskowicz M, Bogdanova N, Bermisheva M, Takhirova Z, Antonenkova N,

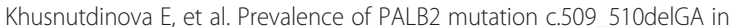
unselected breast cancer patients from Central and Eastern Europe. Fam Cancer. 2014;13(2):137-42.

52. van Der Looij M, Wysocka B, Brozek I, Jassem J, Limon J, Olah E. Founder BRCA1mutations and two novel germline BRCA2 mutations in breast and/or ovarian cancer families from North-Eastern Poland. Hum Mutat. 2000;15(5):480-1.

53. Grzybowska E, Siemińska M, Zientek H, Kalinowska E, Michalska J, UtrackaHutka B, et al. Germline mutations in the BRCA1 gene predisposing to breast and ovarian cancers in Upper Silesia population. Acta Biochim Pol. 2002;49(2):351-6.

54. Rzepecka IK, Szafron L, Stys A, Bujko M, Plisiecka-Halasa J, Madry R, et al. High frequency of allelic loss at the BRCA1 locus in ovarian cancers: clinicopathologic and molecular associations. Cancer Genet. 2012;205(3):94-100.

55. Gaj P, Kluska A, Nowakowska D, Bałabas A, Piątkowska M, Dabrowska M, et al. High frequency of BRCA1 founder mutations in Polish women with nonfamilial breast cancer. Fam Cancer. 2012;11(4):623-8. 